Article

\title{
Determination of the Mechanical Properties of PIN-PMN-PT Bulk Single Crystals by Nanoindentation
}

\author{
Weiguang Zhang ${ }^{1,+}$, Jijun Li ${ }^{1,2, *}+{ }^{\dagger}$, Yongming Xing ${ }^{1}$, Fengchao Lang ${ }^{1}$, Chunwang Zhao ${ }^{1,2}$, \\ Xiaohu Hou ${ }^{3}$, Shiting Yang ${ }^{1}$ and Guisheng $\mathrm{Xu}{ }^{4}$ \\ 1 College of Science, Inner Mongolia University of Technology, Hohhot 010051, China; \\ zhangwg@imut.edu.cn (W.Z.); xym@imut.edu.cn (Y.X.); langfengchao@aliyun.com (F.L.); \\ cwzhao@shmtu.edu.cn (C.Z.); yang8191384@163.com (S.Y.) \\ 2 College of Arts and Sciences, Shanghai Maritime University, Shanghai 201306, China \\ 3 Test Center, Inner Mongolia University of Technology, Hohhot 010051, China; houxiaohuhu@163.com \\ 4 Shanghai Institute of Ceramics, Chinese Academy of Sciences, Shanghai 201899, China; \\ guishengxu@mail.sic.ac.cn \\ * Correspondence: ji_jun_li@163.com \\ + These authors contributed equally to this work and should be considered co-first author.
}

Received: 24 November 2019; Accepted: 5 January 2020; Published: 8 January 2020

\begin{abstract}
The present study aimed to experimentally evaluate the mechanical properties of $\mathrm{Pb}\left(\mathrm{In}_{1 / 2} \mathrm{Nb}_{1 / 2}\right) \mathrm{O}_{3}-\mathrm{Pb}\left(\mathrm{Mg}_{1 / 3} \mathrm{Nb}_{2 / 3}\right) \mathrm{O}_{3}-\mathrm{PbTiO}_{3}$ (PIN-PMN-PT) bulk single crystals with different crystallographic directions using the nanoindentation technique. The load-indentation depth curves, elastic and plastic deformations, hardnesses, and Young's moduli of [100]- and [110]-oriented 0.28PIN-0.43PMN-0.29PT bulk single crystals were investigated. Our results show that with an increase in the maximum indentation depth $h_{\max }$, the plastic residual percentage increased for both the [100]- and the [110]-oriented single crystals. At each $h_{\max }$, the plastic residual percentage of the [100]-oriented PIN-PMN-PT single crystals was less than that of the [110]-oriented PIN-PMN-PT single crystals. At $h_{\max }$ from $500 \mathrm{~nm}$ to $2000 \mathrm{~nm}$, the plastic deformation was larger than the elastic deformation, and the plastic residual percentage was larger than $50 \%$ for both the [100]and the [110]-oriented single crystals. This means that the plastic deformation dominated in the indentation process of PIN-PMN-PT single crystals. The indentation size effect on the hardness of the PIN-PMN-PT single crystals was apparent in the nanoindentation process. Both the hardness and the Young's modulus of the [100]-PIN-PMN-PT single crystals were greater than those of the [110]-PIN-PMN-PT single crystals, which indicates that the PIN-PMN-PT single crystals had anisotropic mechanical characteristics.
\end{abstract}

Keywords: relaxor-based ferroelectric PIN-PMN-PT single crystal; nanoindentation; load-depth curves; elastic and plastic deformation; hardness; Young's modulus

\section{Introduction}

In the last 15 years, because of their excellent piezoelectric properties, relaxor-based ferroelectric single crystals such as binary $\mathrm{Pb}\left(\mathrm{Mg}_{1 / 3} \mathrm{Nb}_{2 / 3}\right) \mathrm{O}_{3}-\mathrm{PbTiO}_{3} \quad(\mathrm{PMN}-\mathrm{PT})$ and ternary $\mathrm{Pb}\left(\mathrm{In}_{1 / 2} \mathrm{Nb}_{1 / 2}\right) \mathrm{O}_{3}-\mathrm{Pb}\left(\mathrm{Mg}_{1 / 3} \mathrm{Nb}_{2 / 3}\right) \mathrm{O}_{3}-\mathrm{PbTiO}_{3}$ (PIN-PMN-PT) have attracted extensive attention and become important materials in the fabrication of new-generation high-performance electromechanical devices including ultrasound transducers, actuators, sensors, and other electromechanical devices [1-9]. It is worth noting that due to the high toxicity of lead, the traditional lead-containing ferro-piezoelectric materials are very harmful to the environment and human health. Lead-free materials are therefore the 
future developmental direction of ferro-piezoelectric materials [10-13]. However, current lead-free piezoelectric materials have some defects which limit their applications, and so lead-containing materials continue to dominate in a number of applications. With its concentration of PT near the morphotropic phase boundary region, the ternary PIN-PMN-PT single crystal not only has similar piezoelectric performance to that of the binary PMN-PT single crystal but also possesses higher phase transition temperature $\left(>120^{\circ} \mathrm{C}\right)$ and coercive field $(\sim 6 \mathrm{kV} / \mathrm{cm})$ than the binary PMN-PT single crystal. These properties are very crucial to many electromechanical devices, especially when applied to high-drive and high-temperature environments [14-16].

In practical applications, relaxor-based ferroelectric single crystals are expected to endure mechanical loading [17-20]. Moreover, mechanical loading may also degrade the performance of ferroelectric single-crystal devices, eventually leading to device failure during fabrication or service [21-24]. Understanding the mechanical properties of relaxor-based ferroelectric PIN-PMN-PT single crystals is therefore key to improving the performance and optimizing the design of these devices.

Nanoindentation is a convenient and reliable examination method to investigate mechanical properties with small volumes and has been widely used to examine various materials [25-29]. Nanoindentation is a continuous measurement of the load and displacement. Then, nano-mechanical properties such as hardness, Young's modulus, indentation strain-rate sensitivity, and creep can be measured from the load-displacement curve. The mechanical behavior of the relaxor-based ferroelectric single crystals has been studied by some researchers. Gailard et al. presented a study of the deformation mechanisms of $\mathrm{BaTiO}_{3}$ giant single crystals with known orientations using nanoindentation and an atomic force microscope [30]. Fang et al. investigated the interactions between the crack propagation and domain switching in poled $\mathrm{BaTiO}_{3}$ single crystals under a mechanical load [31]. Babu et al. performed the Vickers microhardness test on a $<001>-$ cut $\mathrm{Na}_{1 / 2} \mathrm{Bi}_{1 / 2} \mathrm{TiO}_{3}$ single crystal and calculated its fracture toughness and brittleness index from the R-curve [32]. Zhou et al. investigated the electric field-dependent mechanical properties of the PMN-PT single crystal by electromechanical-coupled nanoindentation [33]. Zeng et al. investigated the deformation and mechanical properties of a (001)-oriented single crystal of PZN-0.07PT using a combination of nanoindentation, micro-indentation, and three-point bending tests [34]. These studies examined in part the mechanical behavior of the relaxor-based ferroelectric single crystals, but there has been little investigation into the mechanical properties of ternary PIN-PMN-PT single crystals using the nanoindentation technique.

In the present work, the anisotropic nano-mechanical properties of relaxor-based ferroelectric PIN-PMN-PT bulk single crystals with different crystallographic directions were experimentally investigated using nanoindentation testing. The load-indentation depth curves, elastic and plastic deformations, hardnesses. and Young's moduli of the [100]- and [110]-oriented PIN-PMN-PT bulk single crystals were evaluated.

\section{Experimental Method}

The ferroelectric $0.28 \mathrm{PIN}-0.43 \mathrm{PMN}-0.29 \mathrm{PT}$ single crystals used in this study were grown using a modified Bridgeman method and were provided by the Shanghai Institute of Ceramics, Chinese Academy of Sciences. High-purity (99.99\%) oxide powders of $\mathrm{PbO}, \mathrm{In}_{2} \mathrm{O}_{3}, \mathrm{Nb}_{2} \mathrm{O}_{5}, \mathrm{MgO}$, and $\mathrm{TiO}_{2}$ were mixed stoichiometrically and ground to reduce the particle size. The resulting powder was sintered for 8 hours at $1000^{\circ} \mathrm{C}$. The sintered material was put into a platinum crucible, and the crucible was sealed and placed inside a furnace. The sintered material was heated up to $1400^{\circ} \mathrm{C}$, and the melt was equilibrated for 10 hours. Lastly, the crucible was lowered at $0.5 \mathrm{~mm} / \mathrm{hour}$, and the crystal was grown. The PIN-PMN-PT single crystal was cut into a rectangular specimen with dimensions of $6 \times 4 \times 0.5 \mathrm{~mm}^{3}$. The crystallographic direction of the main plane $(6 \times 4 \mathrm{~mm})$ was either the [100] direction (termed the [100]-oriented PIN-PMN-PT single crystal) or the [110] direction (termed the [110]-oriented PIN-PMN-PT single crystal). 
For the purpose of consistency and accuracy of the nanoindentation testing results, the main planes $(6 \times 4 \mathrm{~mm})$ of the PIN-PMN-PT single-crystal specimens were ground and mechanically and electrolytically polished to a near-mirror finish. Figure 1 shows the $X$-ray diffraction (XRD) patterns from the main planes of [100]- and [110]-oriented PIN-PMN-PT single crystals by using X-ray diffractometer SmartLab 9KW (Rigaku, Akishima, Tokyo, Japan). It reveals that the PIN-PMN-PT single crystals with two different crystallographic directions in this study were exactly in the [100] and [110] directions and additionally had good phase purity.

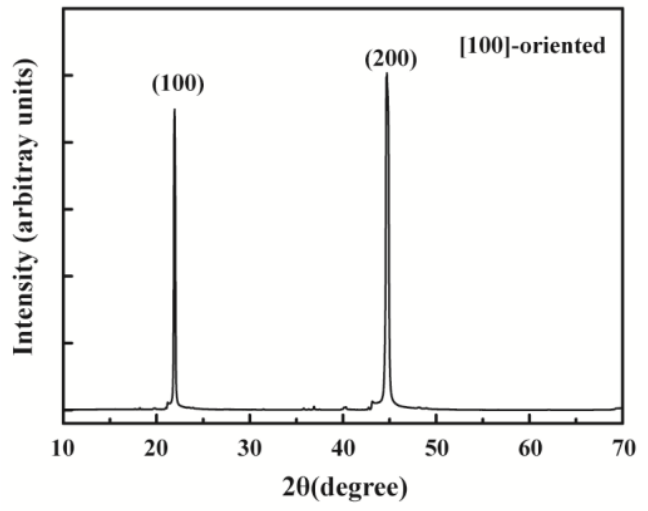

(a)

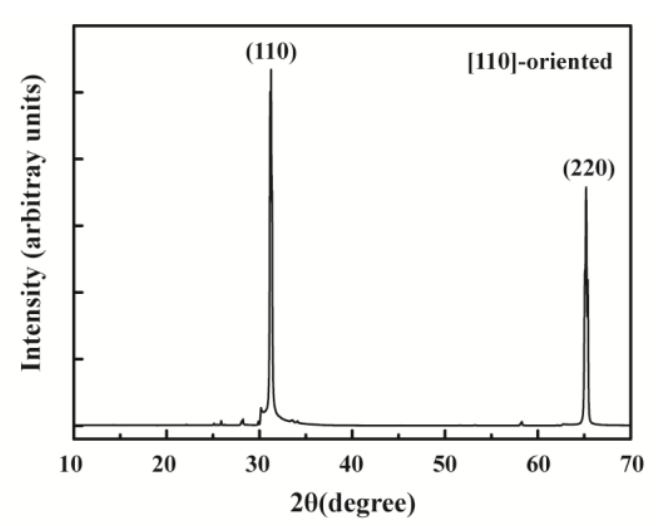

(b)

Figure 1. XRD patterns from the main planes of (a) [100]- and (b) [110]-oriented $\mathrm{Pb}\left(\mathrm{In}_{1 / 2} \mathrm{Nb}_{1 / 2}\right) \mathrm{O}_{3}-\mathrm{Pb}\left(\mathrm{Mg}_{1 / 3} \mathrm{Nb}_{2 / 3}\right) \mathrm{O}_{3}-\mathrm{PbTiO}_{3}$ (PIN-PMN-PT) single crystals.

The mechanical properties of the PIN-PMN-PT single crystals were characterized using a Nano indenter G200 (Agilent Technologies, Santa Clara, CA, USA) with a standard diamond Berkovich indenter (Agilent Technologies, Santa Clara, CA, USA) at room temperature. For the Berkovich indenter, the centerline-to-face angle, centerline-to-edge angle, and radius at the tip were $65.3^{\circ}, 77.05^{\circ}$, and $50 \mathrm{~nm}$, respectively. The Nano indenter G200 had a maximum load of $500 \mathrm{mN}$ and a maximum indentation depth greater than $500 \mu \mathrm{m}$. With a load resolution of $50 \mathrm{nN}$ and displacement resolution less than $0.01 \mathrm{~nm}$, it could accurately test the mechanical behavior of the material at both the microand the nano-scale. The nanoindentation measurements were conducted under continuous stiffness measurement (CSM) procedures [35-37]. The indentation loads acted on the main planes $(6 \times 4 \mathrm{~mm})$ of the [100]- and [110]-oriented PIN-PMN-PT single crystal samples at a constant strain rate of 0.05 $\mathrm{s}^{-1}$ with four maximum indentation depths of $500 \mathrm{~nm}, 1000 \mathrm{~nm}, 1500 \mathrm{~nm}$, and $2000 \mathrm{~nm}$. When the indentation depth reached the maximum value, the corresponding peak load was held for $10 \mathrm{~s}$ and then unloaded at the same strain rate. More than five indents at each maximum indentation depth were performed on the samples to confirm the reliability and repeatability of the nanoindentation tests. For the sake of eliminating interactions among the indentation points, the spacing between each two neighboring indentation points was set to $100 \mu \mathrm{m}$.

During indenting, loads and displacements were recorded to generate load-indentation depth curves. The Oliber-Pharr method was applied to determine the hardness $(H)$ as well as the Young's modulus $(E)[38,39]$. The $H$ and $E$ were calculated using the following relationships:

$$
\begin{gathered}
H=\frac{P_{\max }}{A\left(h_{c}\right)}, \\
A\left(h_{c}\right)=24.5 h_{c}^{2}, \\
E_{r}=\frac{S \sqrt{\pi}}{2 \beta \sqrt{A}},
\end{gathered}
$$




$$
E=\left(1-v^{2}\right)\left[\frac{1}{E_{r}}-\frac{\left(1-v_{i}^{2}\right)}{E_{i}}\right]^{-1},
$$

where $P_{\max }$ is the maximum applied load, and $A$ is the projected contact area between the indenter tip and the specimen at the maximum load; $h_{c}$ is the contact indentation depth determined from load-indentation depth curves; $E_{r}$ is the reduced modulus; $E_{i}$ and $v_{i}$ are Young's modulus and Poisson's ratio for the diamond indenter, with $E_{i}=1141 \mathrm{GPa}$, and $v_{i}=0.07 ; \mathrm{S}$ is the initial unloading stiffness determined by the slope of the unloading curve $\mathrm{d} P / \mathrm{d} h$ at the maximum load, and $\beta$ is the correction factor that depends on the geometry of the indenter (for the Berkovich tip, $\beta$ is 1.034).

\section{Results and Discussion}

\subsection{Load-Indentation Depth Curves}

Figure 2 shows the representative load-indentation depth curves at different maximum indentation depths for the [100]- and [110]-oriented PIN-PMN-PT bulk single crystals. It is observed that the load-indentation depth curves for each maximum indentation depth closely overlap when the maximum indentation depth $h_{\max }$ is below $1500 \mathrm{~nm}$. The difference between the load-indentation depth curves at the $h_{\max }$ of $2000 \mathrm{~nm}$ is very small. Thus, the load-indentation depth curves exhibit a low noise level and small variation in the data. These features reflect the good phase purity and crystal uniformity of the PIN-PMN-PT bulk single crystal, which is consistent with the XRD results above.

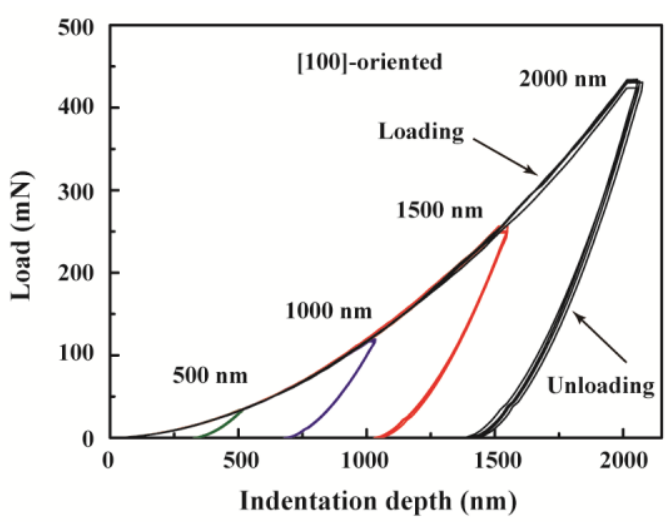

(a)

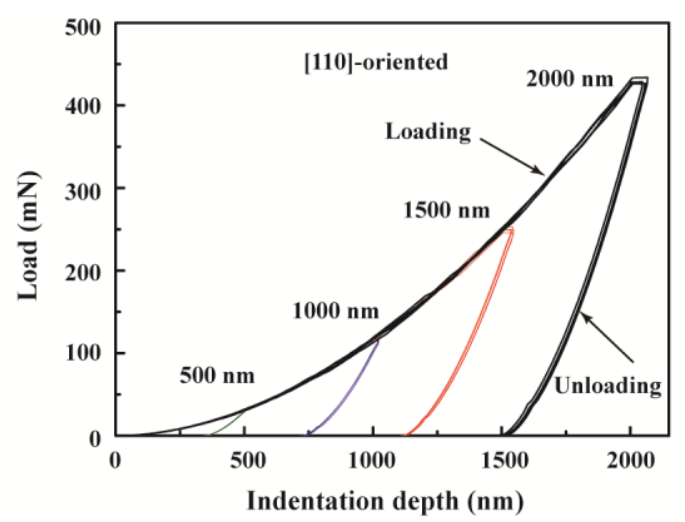

(b)

Figure 2. Load-indentation depth curves at different maximum depths for (a) the [100]-oriented PIN-PMN-PT bulk single crystal and (b) the [110]-oriented PIN-PMN-PT bulk single crystal during the nanoindentation test.

With the indentation depth increasing, the load increased gradually at each $h_{\max }$ during the loading process, and with the $h_{\max }$ increasing, the corresponding peak load also gradually increased. It can be seen that when the $h_{\max }$ increased from $500 \mathrm{~nm}$ to $2000 \mathrm{~nm}$, the corresponding peak load increased from $34.22 \mathrm{mN}$ to $436.54 \mathrm{mN}$ for the [100]-oriented PIN-PMN-PT bulk single crystal and from $31.33 \mathrm{mN}$ to $428.68 \mathrm{mN}$ for the [110]-oriented PIN-PMN-PT bulk single crystal.

When the indentation depth reached the $h_{\max }$, the corresponding peak load was held for $10 \mathrm{~s}$ and then unloaded. Only the elastic indentation depth recovered in the unloading process. After unloading, the indentation depth did not fully recover, and residual indentation depth remained, which indicated irreversible plastic deformation in the PIN-PMN-PT bulk single crystal during the loading process. In our experiment, there was no discontinuity in the load-indentation depth curves within an indentation depth of $2000 \mathrm{~nm}$, which indicated that large cracks were not formed in the PIN-PMN-PT single crystal during the loading and unloading process. 


\subsection{Elastic and Plastic Deformations}

Figure 3 shows the elastic and plastic deformations versus the maximum indentation depth $h_{\max }$ for the [100]- and [110]-oriented PIN-PMN-PT single crystals. It can be seen that when the $h_{\max }$ increased from $500 \mathrm{~nm}$ to $2000 \mathrm{~nm}$, the elastic deformation increased from $181.88 \mathrm{~nm}$ to 630.27 $\mathrm{nm}$ for the [100]-oriented PIN-PMN-PT bulk single crystal and from $155.78 \mathrm{~nm}$ to $547.47 \mathrm{~nm}$ for the [110]-oriented PIN-PMN-PT bulk single crystal. At each $h_{\max }$, the elastic deformation of the [100]-oriented PIN-PMN-PT bulk single crystal was larger than that of the [110]-oriented PIN-PMN-PT bulk single crystal. A similar relationship was observed in the plastic deformation results. With increasing the $h_{\max }$ from 500 to $2000 \mathrm{~nm}$, the plastic deformation increased from $334.67 \mathrm{~nm}$ to 1436.96 $\mathrm{nm}$ for the [100]-oriented PIN-PMN-PT bulk single crystal and from $354.94 \mathrm{~nm}$ to $1499.36 \mathrm{~nm}$ for the [110]-oriented PIN-PMN-PT bulk single crystal. At each $h_{\max }$, the plastic deformation of the [100]-oriented PIN-PMN-PT bulk single crystal was less than that of the [110]-oriented PIN-PMN-PT bulk single crystal.

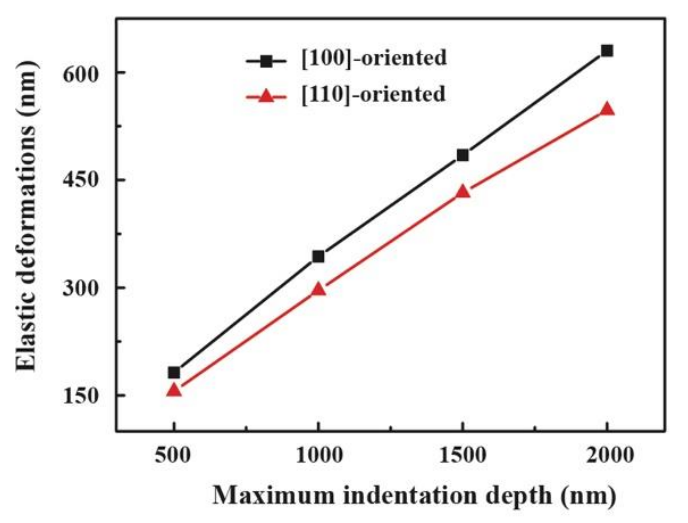

(a)

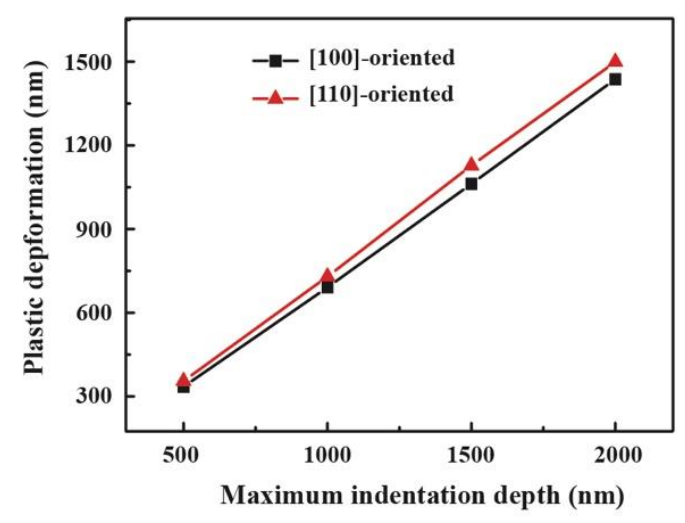

(b)

Figure 3. (a) Elastic deformation and (b) plastic deformation versus maximum indentation depth for the [100]- and [110]-oriented PIN-PMN-PT single crystals.

The elastic recovery and the plastic residual percentages versus the maximum indentation depth $h_{\max }$ for the [100]- and [110]-oriented PIN-PMN-PT single crystals are shown in Figure 4 . It can be seen that with increasing the $h_{\max }$, the elastic recovery percentage decreased from $35.21 \%$ to $30.49 \%$ for the [100]-oriented PIN-PMN-PT crystal and from $30.50 \%$ to $26.75 \%$ for the [110]-oriented PIN-PMN-PT crystal. At each $h_{\max }$, the elastic recovery percentage of the [100]-oriented PIN-PMN-PT crystal was larger than that of the [110]-oriented PIN-PMN-PT crystal. Conversely, with increasing the $h_{\max }$, the plastic residual percentage increased from $64.79 \%$ to $69.51 \%$ for the [100]-oriented PIN-PMN-PT crystal and from $69.50 \%$ to $73.25 \%$ for the [110]-oriented PIN-PMN-PT bulk single crystal. At each $h_{\text {max }}$, the plastic residual percentage of the [100]-oriented PIN-PMN-PT bulk single crystal was less than that of the [110]-oriented PIN-PMN-PT bulk single crystal. This indicated that the higher the maximum indentation depth $h_{\max }$ or peak load, the lower the elastic recovery percentage and the higher the plastic residual percentage in the PIN-PMN-PT bulk single crystals. Under indentation stress, some of the domains of the PIN-PMN-PT bulk single crystals tend to switch, forming non-180 domain walls to minimize elastic energy [40]. The formation of these non-180 domain walls may cause irreversible depolarization, relieving the internal stress built up in the PIN-PMN-PT bulk single crystals [41]. This reduces the driving force for the recovery of the PIN-PMN-PT bulk single crystal. Therefore, at the maximum indentation depth of $500 \mathrm{~nm}$ to $2000 \mathrm{~nm}$, the plastic deformation is larger than the elastic deformation, and the plastic residual percentage is larger than $50 \%$, which means that the plastic deformation dominated in the indentation process of the PIN-PMN-PT bulk single crystal. 


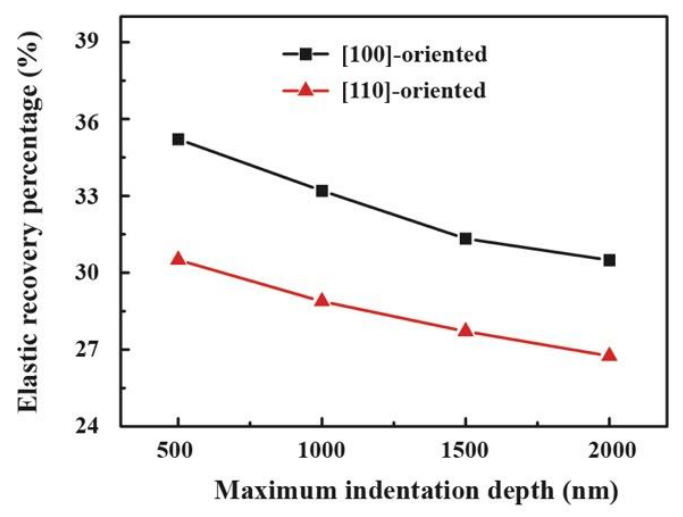

(a)

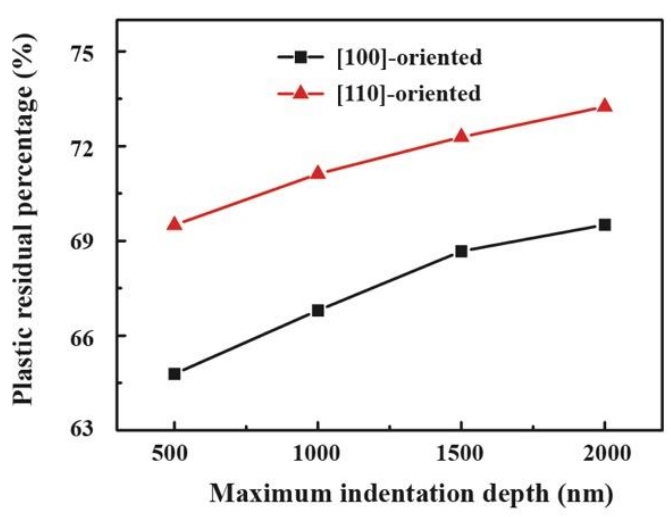

(b)

Figure 4. (a) Elastic recovery percentage and (b) plastic residual percentage versus maximum indentation depth for the [100]- and [110]-oriented PIN-PMN-PT single crystals.

\subsection{Hardness and Young's Modulus}

Figures 5 and 6 show the hardness-indentation depth curves and Young's modulus -indentation depth curves, respectively, of the [100]- and [110]-oriented PIN-PMN-PT single crystals at the maximum indentation depths from $500 \mathrm{~nm}$ to $2000 \mathrm{~nm}$. It can be seen that when the indentation depth was less than $30 \mathrm{~nm}$, the fluctuation of the data was somewhat large, which may be related to the resolution of the nano-indenter, the smoothness of the specimen surface, and environmental noise when searching for the initial contact position during the nanoindentation test. However, when the indentation depth was more than $30 \mathrm{~nm}$, the hardness-indentation depth curves and Young's modulus-indentation depth curves featured small variation in the data at the same range of indentation depth.

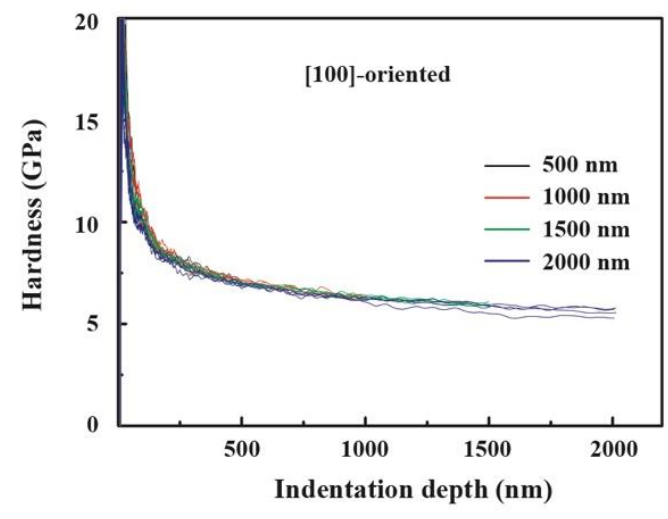

(a)

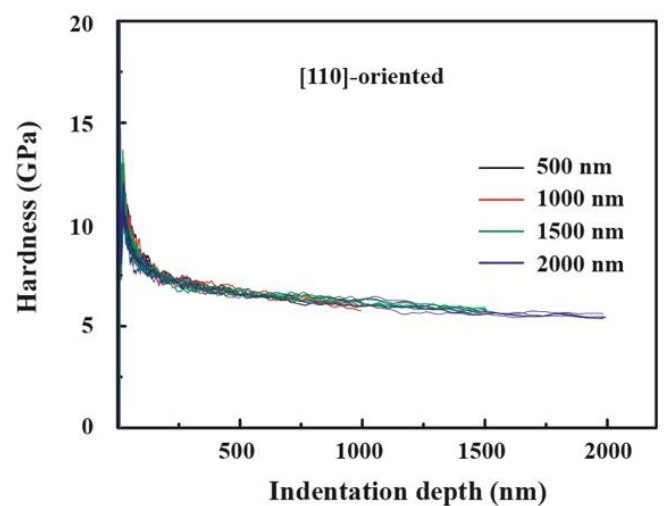

(b)

Figure 5. Hardness-indentation depth curves of the (a) [100]- and (b) [110]-oriented PIN-PMN-PT single crystals at the maximum indentation depths from $500 \mathrm{~nm}$ to $2000 \mathrm{~nm}$.

To compare the hardnesses and Young's moduli of the [100]-and [110]-oriented PIN-PMN-PT bulk single crystals, the hardness and Young's modulus were determined as the average of the values of four indentations at every indentation depth, with maximum indentation depth of $2000 \mathrm{~nm}$. The corresponding hardness-indentation depth curves and the Young's modulus-indentation depth curves of the [100]- and [110]-oriented PIN-PMN-PT bulk single crystals are shown in Figures 7 and 8 , respectively. 


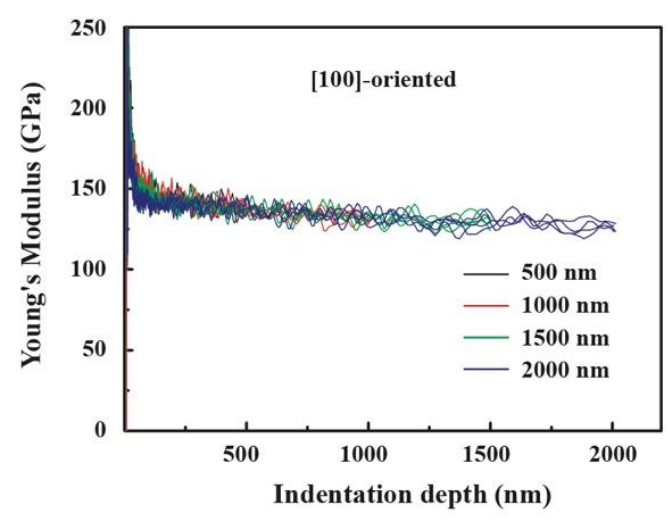

(a)

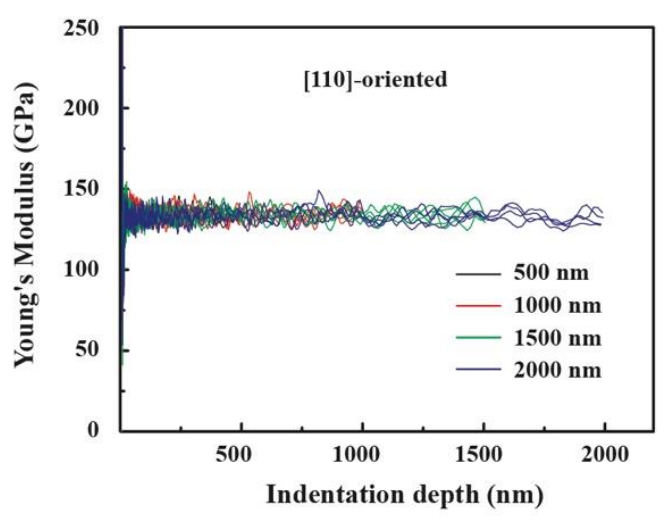

(b)

Figure 6. Young's modulus-indentation depth curves of the (a) [100]- and (b) [110]-oriented PIN-PMN-PT single crystals at the maximum indentation depths from $500 \mathrm{~nm}$ to $2000 \mathrm{~nm}$.

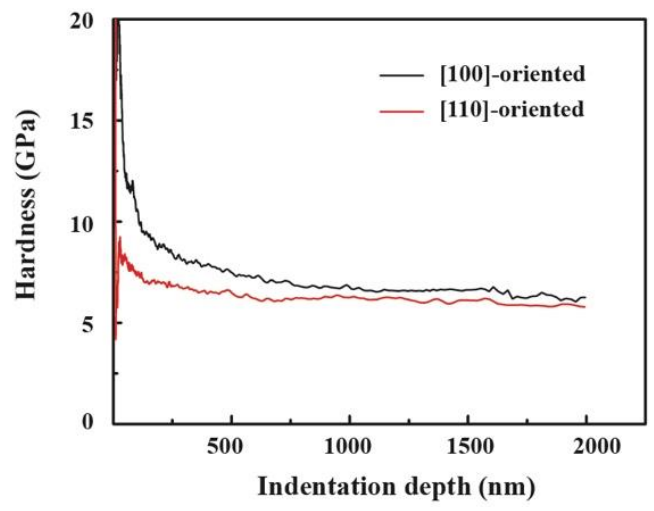

Figure 7. Hardness-indentation depth curves of the [100]- and [110]-oriented PIN-PMN-PT bulk single crystals.

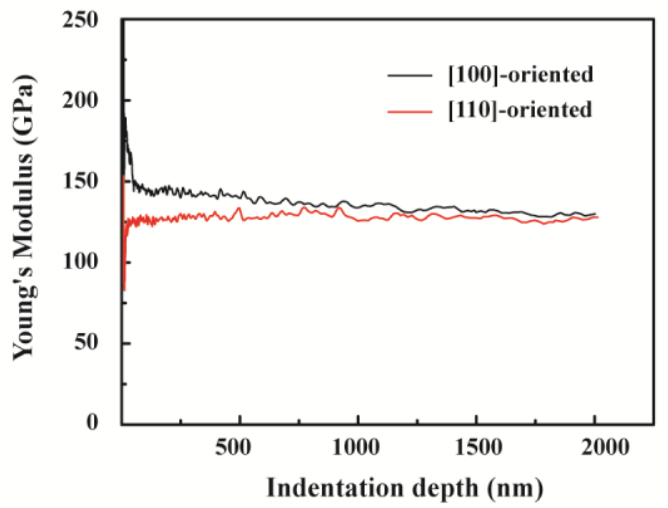

Figure 8. Young's modulus-indentation depth curves of the [100]- and [110]-oriented PIN-PMN-PT bulk single crystals.

From Figure 7, it can be seen that with increasing indentation depth from $30 \mathrm{~nm}$ to $500 \mathrm{~nm}$, the hardness decreased from 16.92 GPa to 7.50 GPa for the [100]-oriented PIN-PMN-PT bulk single crystal and from 8.46 GPa to 6.47 GPa for the [110]-oriented PIN-PMN-PT bulk single crystal. This indicated that the hardness decreased dramatically with the increase of the indentation depth from 30 $\mathrm{nm}$ to $500 \mathrm{~nm}$. When the indentation depth exceeded $500 \mathrm{~nm}$, the decreasing tendencies gradually slowed. When the indentation depth was more than $1300 \mathrm{~nm}$, the hardness tended to be stable. Therefore, the indentation size effect on the hardness of the PIN-PMN-PT bulk single crystal appeared during the nanoindentation process. This indentation size effect is usually attributed to the large 
surface strain gradient and work hardening [42,43]. From Figure 8, it can be seen that the Young's modulus was almost independent of the indentation depth in the nanoindentation process.

The average hardness and Young's modulus were evaluated in the indentation depth range from 1400 to $1600 \mathrm{~nm}$, as shown in Figures 7 and 8, respectively. The average hardnesses of the [100]- and [110]-oriented PIN-PMN-PT bulk single crystals were $5.98 \mathrm{GPa}$ and $5.53 \mathrm{GPa}$, respectively. The average Young's modulus of the [100]- and [110]-oriented PIN-PMN-PT bulk single crystals were $136.45 \mathrm{GPa}$ and 132.74 GPa, respectively. Thus, both the hardness and Young's modulus of the [100]-oriented PIN-PMN-PT bulk single crystal were a little larger than those of the [110]-oriented PIN-PMN-PT bulk single crystal, which indicated anisotropic mechanical characteristics in the PIN-PMN-PT bulk single crystal. The hardness and Young's modulus reflect the resistance to plastic and elastic deformations, respectively. Therefore, the PIN-PMN-PT single crystal can endure more mechanical load and has higher stiffness and lower friction coefficient and wear rate in the [100] crystallographic direction. The PIN-PMN-PT single crystal can be more easily polished and subjected to ductile machining in the [110] crystallographic direction. The anisotropy of its mechanical characteristics is mainly attributed to the arrangement differences of its atoms, in different crystallographic directions. This anisotropy of the mechanical properties may also have some effect on the piezoelectric properties of PIN-PMN-PT single crystals.

\section{Conclusions}

The load-indentation depth curves, elastic and plastic deformations, hardnesses, and Young's moduli of the [100]- and [110]-oriented relaxor-based ferroelectric 0.28PIN-0.43PMN-0.29PT bulk single crystals were investigated by the nanoindentation technique and continuous stiffness measurements. The conclusions are as follows:

(1) The load-indentation depth curves for the PIN-PMN-PT bulk single crystals featured a low noise level and small variation in the data, which reflects the good phase purity and uniformity of the PIN-PMN-PT bulk single crystals. There was no discontinuity in the load-indentation depth curves within an indentation depth of $2000 \mathrm{~nm}$, which indicates that large cracks were not formed in the PIN-PMN-PT single crystals during the loading and unloading processes.

(2) With increasing the maximum indentation depth $h_{\max }$ from $500 \mathrm{~nm}$ to $2000 \mathrm{~nm}$, both the elastic and the plastic deformations increased for both the [100]- and the [110]-oriented single crystals. However, with the increasing $h_{\max }$, the elastic recovery percentage decreased, and the plastic residual percentage increased for both the [100]- and [110]-oriented single crystals. At each $h_{\max }$, the elastic recovery percentage of the [100]-oriented PIN-PMN-PT bulk single crystal was larger than that of the [110]-oriented PIN-PMN-PT bulk single crystal, and the plastic residual percentage of the [100]-oriented PIN-PMN-PT bulk single crystal was less than that of the [110]-oriented PIN-PMN-PT bulk single crystal. In the $h_{\max }$ from $500 \mathrm{~nm}$ to $2000 \mathrm{~nm}$, the plastic deformation was larger than the elastic deformation, and the plastic residual percentage was larger than $50 \%$ for both the [100]- and [110]-oriented single crystals, which means that the plastic deformation dominated in the indentation process of the PIN-PMN-PT bulk single crystals.

(3) The indentation size effect on the hardness of the PIN-PMN-PT bulk single crystals was apparent, which is usually attributed to the large surface strain gradient and work hardening. The Young's modulus was almost independent of the indentation depth in the nanoindentation process. Both the hardness and the Young's modulus of the [100] PIN-PMN-PT bulk single crystal were a little larger than those of the [110] PIN-PMN-PT bulk single crystal, which indicates that the PIN-PMN-PT bulk single crystal had anisotropic mechanical characteristics. These anisotropic mechanical characteristics were mainly attributed to the arrangement of atoms in different crystallographic directions. 
Author Contributions: Conceptualization, J.L., W.Z., and Y.X.; methodology, J.L., W.Z., and F.L.; software, J.L., W.Z., and X.H.; validation, J.L., W.Z., and S.Y.; formal analysis, J.L. and W.Z.; investigation, J.L. and W.Z.; resources, G.X.; data curation, J.L. and W.Z.; writing-original draft preparation, J.L. and W.Z.; writing一review and editing, C.Z. and Y.X.; visualization, W.Z.; supervision, J.L.; project administration, J.L.; funding acquisition, J.L. All authors have read and agreed to the published version of the manuscript.

Funding: This research was funded by the National Science Foundation of China (Grant No. 11562016, 11762014, 11762013, and 11972221), the Natural Science Foundation of Inner Mongolia Autonomous Region (Grant No. 2018MS01013 and 2013MS0107), and the Science Research Project of Inner Mongolia University of Technology (Grant No. X201713 and ZZ201812).

Acknowledgments: The authors express their greatest thanks to Jingfeng Wang for his excellent technical support.

Conflicts of Interest: The authors declare no conflict of interest.

\section{References}

1. Wadhawan, V.K.; Pandit, P.; Gupta, S.M. PMN-PT based relaxor ferroelectrics as very smart materials. Mater. Sci. Eng. B 2005, 120, 199-205. [CrossRef]

2. Zhang, R.; Jiang, B.; Cao, W.W. Elastic, piezoelectric, and dielectric properties of multidomain $0.67 \mathrm{~Pb}\left(\mathrm{Mg}_{1 / 3} \mathrm{Nb}_{2 / 3}\right) \mathrm{O}_{3}-0.33 \mathrm{PbTiO}_{3}$ single crystals. J. Appl. Phys. 2001, 90, 3471-3475. [CrossRef]

3. Li, F.; Zhang, S.J.; Xu, Z.; Wei, X.Y.; Luo, J.; Shrout, T.R. Temperature independent shear piezoelectric response in relaxor-PbTiO 3 based crystals. Appl. Phys. Lett. 2010, 97, 252903. [CrossRef] [PubMed]

4. Sun, E.W.; Cao, W.W. Relaxor-based ferroelectric single crystals: Growth, domain engineering, characterization and applications. Prog. Mater. Sci. 2014, 65, 124-210. [CrossRef] [PubMed]

5. Straub, F.K.; Ngo, H.T.; Aanad, V.; Domzalski, D.B. Development of a piezoelectric actuator for trailing edge flap control of full scale rotor blades. Smart Mater. Struct. 2001, 10, 25-34. [CrossRef]

6. Das, S.; Herklotz, A.; Guo, E.J.; Dörr, K. Static and reversible elastic strain effects on magnetic order of $\mathrm{La}_{0.7} \mathrm{Ca}_{0.3} \mathrm{MnO}_{3} / \mathrm{SrTiO}_{3}$ superlattices. J. Appl. Phys. 2014, 115, 143902. [CrossRef]

7. Guo, E.J.; Roth, R.; Das, S.; Dörr, K. Strain induced low mechanical switching force in ultrathin $\mathrm{PbZr}_{0.2} \mathrm{Ti}_{0.8} \mathrm{O}_{3}$ films. Appl. Phys. Lett. 2014, 105, 012903. [CrossRef]

8. Das, S.; Herklotz, A.; Pippel, E.; Guo, E.J.; Rata, D.; Dörr, K. Strain dependence of antiferromagnetic interface coupling in $\mathrm{La}_{0.7} \mathrm{Sr}_{0.3} \mathrm{MnO}_{3} / \mathrm{SrRuO}_{3}$ superlattices. Phys. Rev. B 2015, 91, 134405. [CrossRef]

9. Guo, E.J.; Roth, R.; Das, S.; Herklotz, A.; Dörr, K. Strain-induced improvement of retention loss in $\mathrm{PbZr}_{0.2} \mathrm{Ti}_{0.8} \mathrm{O}_{3}$ films. Appl. Phys. Lett. 2015, 106, 072904. [CrossRef]

10. Trolier-McKinstry, S.; Zhang, S.J.; Bell, J.A.; Tan, X.L. High-performance piezoelectric crystals, ceramics, and films. Annu. Rev. Mater. Res. 2018, 48, 191-217. [CrossRef]

11. Xie, Q.X.; Hu, Y.Q.; Zhao, X.Y.; Wang, F.F.; Tang, Y.X.; Zhang, Q.Z.; Chen, M.Z.; Shi, W.Z.; Lin, D.; Luo, H.S. Theoretical analysis of high electromechanical coupling surface acoustic wave propagating on lead-free $\mathrm{Na}_{0.5} \mathrm{Bi}_{0.5} \mathrm{TiO}_{3}-\mathrm{BaTiO}_{3}$ single crystal. Scr. Mater. 2020, 178, 372-375. [CrossRef]

12. Guo, E.J.; Herklotz, A.; Roth, R.; Christl, M.; Das, S. Tuning the switching time of $\mathrm{BiFeO}_{3}$ Capacitors by Electrodes' conductivity. Appl. Phys. Lett. 2013, 103, 022905. [CrossRef]

13. Guo, E.J.; Das, S.; Herklotz, A. Enhancement of switching speed of $\mathrm{BiFeO}_{3}$ capacitors by magnetic fields. APL Mater. 2014, 2, 096107. [CrossRef]

14. Kim, J.; Yamanaka, S.; Murayama, I.; Katou, T.; Nakayama, T.; Takeda, M.; Yamada, N.; Nishihata, Y.; Fukuda, T.; Tanaka, H.; et al. Temperature stability of PIN-PMN-PT ternary ceramics during pyroeletric power generation. J. Alloys Compd. 2018, 768, 22-27. [CrossRef]

15. Luo, L.; Zhao, X.; Luo, H. Single Crystal PZN-PT, PMN-PT, PSN-PT, and PIN-PT-Based Piezoelectric Materials. In Advanced Piezoelectric Materials: Science and Technology, 2nd ed.; Uchino, K., Ed.; Elsevier Science \& Technology Publishing: Cambridge, UK, 2017; pp. 271-318.

16. Sun, E.W.; Cao, W.W.; Han, P.D. Complete set of material properties of $[011]_{\mathrm{c}}$ poled $0.24 \mathrm{~Pb}\left(\operatorname{In}_{1 / 2} \mathrm{Nb}_{1 / 2}\right)$ $\mathrm{O}_{3}-0.46 \mathrm{~Pb}\left(\mathrm{Mg}_{1 / 3} \mathrm{Nb}_{2 / 3}\right) \mathrm{O}_{3}-0.30 \mathrm{PbTiO}_{3}$ single crystal. Mater. Lett. 2011, 65, 2855-2857. [CrossRef]

17. Ahart, M.; Somayazulu, M.; Cohen, R.E.; Ganesh, P.; Dera, P.; Mao, H.-K.; Hemley, R.J.; Ren, Y.; Liermann, P.; $\mathrm{Wu}, \mathrm{Z}$.G. Origin of morphotropic phase boundaries in ferroelectrics. Nature 2008, 451, 545-548. [CrossRef]

18. Martin, A.; Khansur, N.H.; Riess, K.; Webber, K.G. Frequency dependence of the relaxor-to-ferroelectric transition under applied electrical and mechanical fields. J. Eur. Ceram. Soc. 2019, 39, 1031-1041. [CrossRef] 
19. Wan, Q.; Chen, C.; Shen, Y.P. Effects of stress and electric field on the electromechanical properties of $\mathrm{Pb}\left(\mathrm{Mg}_{1 / 3} \mathrm{Nb}_{2 / 3}\right) \mathrm{O}_{3}-0.32 \mathrm{PbTiO}_{3}$ single crystals. J. Appl. Phys. 2005, 98, 024103. [CrossRef]

20. Das, S.; Biswal, A.K.; Parida, K.; Choudhary, R.N.P.; Roy, A. Electrical and mechanical behavior of PMN-PT/CNT based polymer composite film for energy harvesting. Appl. Surf. Sci. 2018, 428, 356-363. [CrossRef]

21. Chen, Y.; Xu, J.G.; Xie, S.X.; Nie, R.; Yuan, J.; Wang, Q.Y.; Zhu, J.G. Failure mode, ferroelastic behavior and toughening effect of bismuth titanate ferroelectric ceramics under uniaxial compression load. Mater. Des. 2018, 152, 54-64. [CrossRef]

22. Won, S.S.; Seo, H.; Kawahara, M.; Glinsek, S.; Lee, J.; Kim, Y.; Jeong, C.K.; Kingon, A.I.; Kim, S.-H. Flexible vibrational energy harvesting devices using strain-engineered perovskite piezoelectric thin films. Nano Energy 2019, 55, 182-192. [CrossRef]

23. Fang, X.Q.; Bai, G.X. Preparation and service performance characterization of Ni/PMN-PT: Effect of preparation temperature. J. Alloys Compd. 2018, 735, 1131-1136. [CrossRef]

24. Chen, Y.; Zhang, Y.; Zhang, L.; Ding, F.; Schmidt, O.G. Scalable single crystalline PMN-PT nanobelts sculpted from bulk for energy harvesting. Nano Energy 2017, 31, 239-246. [CrossRef]

25. Muhammad, M.; Masoomi, M.; Torries, B.; Shamsaei, N.; Haghshenas, M. Depth-sensing time-dependent response of additively manufactured Ti-6Al-4V alloy. Addit. Manuf. 2018, 24, 37-46. [CrossRef]

26. Sribalaji, M.; Asiq Rahman, O.S.; Laha, T.; Keshri, A.K. Nanoindentation and nanoscratch behavior of electroless deposited nickel-phosphorous costing. Mater. Chem. Phys. 2016, 177, 220-228. [CrossRef]

27. Guo, H.; Jiang, C.B.; Yang, B.J.; Wang, J.Q. Deformation behavior of Al-rich metallic glasses under nanoindentation. J. Mate. Sci. Technol. 2017, 33, 1272-1277. [CrossRef]

28. Nomura, K.-I.; Chen, Y.-C.; Kalia, R.K.; Nakano, A.; Vashishta, P. Defect migration and recombination in nanoindentation of silica glass. Appl. Phys. Lett. 2011, 99, 111906. [CrossRef]

29. Jiao, Z.-M.; Ma, S.-M.; Yuan, G.-Z.; Wang, Z.-H.; Yang, H.-J.; Qiao, J.-W. Plastic deformation of $\mathrm{Al}_{0.3} \mathrm{CoCrFeNi}$ and $\mathrm{AlCoCrFeNi}$ high-entropy alloys under nanoindentation. J. Mater. Eng. Perform. 2015, 24, 3077-3083. [CrossRef]

30. Gaillard, Y.; Macías, A.H.; Munioz-Saldania, J.; Anglada1, M.; Trápaga, G. Nanoindentation of BaTiO 3 : Dislocation nulcleation and mechanical twinning. J. Phys. D Appl. Phys. 2009, 42, 085502. [CrossRef]

31. Fang, D.N.; Jiang, Y.J.; Li, S.; Sun, C.T. Interactions between domain switching and crack propagation in poled $\mathrm{BaTiO}_{3}$ single crystal under mechanical loading. Acta Mater. 2007, 55, 5758-5767. [CrossRef]

32. Babu, P.R.; Selvamani, R.; Singh, G.; Kalainathan, S.; Babu, R.; Tiwari, B.S. Growth, mechanical and domain structure studies of $\mathrm{Na}_{0.5} \mathrm{Bi}_{0.5} \mathrm{TiO}_{3}$ single ceystal grown by flux growth method. J. Alloys Compd. 2017, 721, 199-204. [CrossRef]

33. Zhou, H.; Pei, Y.M.; Li, F.X.; Luo, H.S.; Fang, D.N. Electric-field-tunable mechanical properties of relaxor ferroelectric single crystal measured by nanoindentation. Appl. Phys. Lett. 2014, 104, 061904. [CrossRef]

34. Zeng, K.Y.; Pang, Y.-S.; Shen, L.; Rajan, K.K.; Lim, L.-C. Elastic modulus, hardness and fracture behavior of $\mathrm{Pb}\left(\mathrm{Zn}_{1 / 3} \mathrm{Nb}_{2 / 3}\right) \mathrm{O}_{3}-\mathrm{PbTiO}_{3}$ single crystal. Mater. Sci. Eng. A 2008, 472, 35-42. [CrossRef]

35. Li, X.D.; Bhushan, B. A review of nanoindentation continuous stiffness measurement technique and its applications. Mater. Charact. 2002, 48, 11-36. [CrossRef]

36. Vachhani, S.J.; Doherty, R.D.; Kalidindi, S.R. Effect of the continuous stiffness measurement on the mechanical properties extracted using spherical nanoindentation. Acta Mater. 2013, 61, 3744-3751. [CrossRef]

37. Li, X.D.; Bhushan, B. Development of continuous stiffness measurement technique for composite magnetic tapes. Scripta. Mater. 2000, 42, 929-935. [CrossRef]

38. Oliver, W.C.; Pharr, G.M. An improved technique for determining hardness and elastic modulus using load and displacement sensing indentation experiment. J. Mater. Res. 1992, 7, 1564-1583. [CrossRef]

39. Pharr, G.M.; Oliber, W.C. Measurement of Thin Film Mechanical properties using nanoindentation. MRS Bull. 1992, 17, 28-33. [CrossRef]

40. Damjanovic, D. Ferroelectric, dielectric and piezoelectric properties of ferroelectric thin films and ceramics. Rep. Prog. Phys. 1998, 61, 1267-1324. [CrossRef]

41. Wong, M.F.; Zeng, K.Y. Elastic-plastic deformation of $\mathrm{Pb}\left(\mathrm{Zn}_{1 / 3} \mathrm{Nb}_{2 / 3}\right) \mathrm{O}_{3}-(6-7) \% \mathrm{PbTiO} 3$ single crystals during nanoindentation. Philos. Mag. 2010, 90, 1685-1700. [CrossRef] 
42. Xiao, X.Z.; Chen, L.R.; Yu, L.; Duan, H.L. Modelling nano-indentation of ion-irradiated FCC single crystals by strain-gradient crystal plasticity theory. Int. J. Plast. 2019, 116, 216-231. [CrossRef]

43. Yonezu, A.; Xu, B.X.; Chen, X. Indentation induced lateral crack in ceramics with surface hardening. Mater. Sci. Eng. A 2009, 507, 226-235. [CrossRef]

(C) 2020 by the authors. Licensee MDPI, Basel, Switzerland. This article is an open access article distributed under the terms and conditions of the Creative Commons Attribution (CC BY) license (http://creativecommons.org/licenses/by/4.0/). 